\title{
Effect of body mass index on recurrence following urethroplasty
}

\author{
David E. Rapp ${ }^{1}$, James T. Mills ${ }^{1}$, Luriel I. Smith-Harrison ${ }^{2}$, Ryan P. Smith ${ }^{1}$, Raymond A. Costabile ${ }^{1}$ \\ ${ }^{1}$ Department of Urology, University of Virginia, Charlottesville, VA, USA; ${ }^{2}$ Department of Urology, Medical College of Wisconsin, Milwaukee, \\ Wisconsin, USA \\ Contributions: (I) Conception and design: All authors; (II) Administrative support: DE Rapp, JT Mills, LI Smith-Harrison, RA Costabile; (III) \\ Provision of study materials or patients: DE Rapp, JT Mills, LI Smith-Harrison, RA Costabile; (IV) Collection and assembly of data: DE Rapp, JT \\ Mills, LI Smith-Harrison, RA Costabile; (V) Data analysis and interpretation: All authors; (VI) Manuscript writing: All authors; (VII) Final approval \\ of manuscript: All authors. \\ Correspondence to: David E. Rapp, MD. Department of Urology, UVA Medical Center, Fontaine Research Park, 500 Ray C. Hunt Drive, \\ Charlottesville, VA 22908, USA. Email: derapp@yahoo.com.
}

Background: Limited investigation exists to understand whether obesity affects outcomes of urethral reconstruction. We sought to assess whether body mass index (BMI) is an independent predictor for stricture recurrence following urethroplasty.

Methods: We performed a retrospective review of patients undergoing urethroplasty between 2007-2014, identifying 137 patients for study inclusion. Data collected included BMI and patient demographic and surgical characteristics, including age, stricture length and location, etiology, and urethroplasty technique. Stricture-free survival analysis was performed using Kaplan-Meier method. Logistic regression was performed to assess predictors for stricture recurrence using both univariate and multivariate models.

Results: Mean patient age and follow-up was $46.7( \pm 16.4)$ years and $91.8( \pm 30.5)$ months, respectively. A recurrence rate of $17 \%$ was identified, with a mean time to recurrence of 29 months. There was no difference when comparing the mean BMI in patients with and without recurrence (28.9 vs. $30.4 \mathrm{~kg} / \mathrm{m}^{2}$, respectively) $(\mathrm{P}=0.4)$. A higher rate of stricture recurrence was seen when comparing the cohort with a $\mathrm{BMI}<25 \mathrm{~kg} / \mathrm{m}^{2}$ versus remaining cohorts (BMI: $25-30 \mathrm{~kg} / \mathrm{m}^{2}$; $\mathrm{BMI}>30 \mathrm{~kg} / \mathrm{m}^{2}$ ). However, in univariate and multivariate analysis, BMI failed to demonstrate statistical significance as a predictor for urethroplasty outcome. On multivariate analysis, fasciocutaneous repair type was predictive of stricture recurrence. No additional potential predictors assessed were found to be significant.

Conclusions: In the present study, BMI did not independently predict for stricture recurrence following urethroplasty.

Keywords: Urethroplasty; recurrence; complications; obesity

Submitted Jun 04, 2018. Accepted for publication Jun 13, 2018.

doi: 10.21037/tau.2018.06.07

View this article at: http://dx.doi.org/10.21037/tau.2018.06.07

\section{Introduction}

Obesity is a global epidemic, with nearly two-thirds of the adult population considered to be overweight [body mass index $(\mathrm{BMI})>25 \mathrm{~kg} / \mathrm{m}^{2}$ ] or obese $\left(\mathrm{BMI}>30 \mathrm{~kg} / \mathrm{m}^{2}\right)(1,2)$. Further, an increasing prevalence in obesity has been seen over the last two decades (1). Men generally demonstrate higher rates of overweight or obesity status, with an estimated $70 \%$ having a BMI $>25 \mathrm{~kg} / \mathrm{m}^{2}$ in 2016 (2).
Similar to other comorbidities and risk factors, obesity is a frequently cited consideration during surgical planning across all surgical specialties. Prior investigation demonstrates an increased risk of peri-operative complication in patients with obesity $(3,4)$. In addition, the rate of surgical failure may be increased in obese cohorts. Finally, obesity is associated with an increased prevalence of other comorbidities that may also influence operative complication and recurrence rates $(3,5)$. 
Urethral stricture disease is a common urologic condition that can result in dysfunctional voiding, renal damage, stone formation, and infectious sequelae (6). In the treatment of urethral strictures, urethroplasty has been demonstrated to be an effective, durable, and cost-effective surgical option (7). However, urethroplasty in the obese patient can be technically challenging. In addition, limited investigation exists to understand whether obesity is an independent risk factor for urethroplasty failure. We sought to assess whether $\mathrm{BMI}$ is an independent predictor for stricture recurrence following urethroplasty.

\section{Methods}

We performed a retrospective case-control analysis of patients undergoing urethroplasty at the University of Virginia between 2007 and 2014. Retrospective review was conducted using the University of Virginia Clinical Data Repository and identified 137 patients with minimum 1-year follow-up and available BMI data. Data collected included patient demographic and surgical characteristics, including patient age, BMI, urethroplasty technique, and stricture characteristics (length, location). In addition, specific focus was placed on outcomes data (recurrence). University of Virginia Institutional Review Board IRB approval was obtained for study protocol (IRB\#17303).

\section{Statistical analysis}

Statistical analysis was performed using R Statistical Software (Foundation for Statistical Computing, Vienna, Austria). Descriptive data were analyzed using Student's $t$-test and Fisher's test. Boxplots were created to visualize BMI differences between outcome groups. Stricturefree survival analysis was performed using Kaplan-Meier method. Data were right censored based on death or last follow-up. For Kaplan-Meier analysis, BMI strata were organized as follows: BMI $<25 \mathrm{~kg} / \mathrm{m}^{2}$, BMI $25-30 \mathrm{~kg} / \mathrm{m}^{2}$, and $\mathrm{BMI}>30 \mathrm{~kg} / \mathrm{m}^{2}$. Logistic regression was performed to assess for variables predictive of stricture recurrence and included univariate and multivariate models.

All tests were two-sided with $\alpha=0.05$. For appropriate analyses, $95 \%$ confidence intervals were calculated. Data are listed as mean ( \pm standard deviation).

\section{Results}

Patient demographic and surgical characteristics are detailed in Table 1. Mean patient age and follow-up was $46.7( \pm 16.4)$ years and $91.8( \pm 30.5)$ months, respectively. A majority of strictures were located in the anterior urethra $(77 \%)$. A variety of stricture etiologies and repair types were seen, with idiopathic (43\%) and EPA (45\%) being the most common etiology and repair types, respectively. In comparison of cohorts, a higher proportion of patients in the no recurrence group had anterior strictures and idiopathic etiology. However, these findings did not demonstrate statistical significance.

A recurrence rate of $17 \%$ was identified. The recurrence rates stratified by BMI cohort were as follows: $20 \%$ $\left(<25 \mathrm{~kg} / \mathrm{m}^{2}\right), 9 \%\left(25-30 \mathrm{~kg} / \mathrm{m}^{2}\right), 19 \%\left(>30 \mathrm{~kg} / \mathrm{m}^{2}\right)$. The mean BMI in patients with versus without recurrence was $28.9( \pm 7.2)$ and $30.4( \pm 10.2) \mathrm{kg} / \mathrm{m}^{2}$, respectively $(\mathrm{P}=0.40)$. The mean time to recurrence was $28.9( \pm 24.9)$ months.

Figure 1 demonstrates the Kaplan-Meier analysis given BMI data. In both univariate and multivariate analysis, BMI failed to demonstrate statistical significance as a predictor for urethroplasty outcome (Tables 2,3). Further, additional potential predictors assessed failed to demonstrate predictive significance on univariate analysis. In multivariate analysis, FC repair type was predictive of stricture recurrence $(\mathrm{P}=0.047)$. During logistic regression analysis, two variables (etiology $=$ infectious; repair type $=$ combined $)$ were removed as modeling was not possible given absence of recurrence patients in these cohorts.

\section{Discussion}

The specific etiology underlying the association of obesity and increased risk of post-operative complication or surgical failure is poorly defined and likely multifactorial. Obesity is associated with an impaired immune response, which likely contributes to the increased rate of surgical site infection reported in obese patients (8). In addition, obesity confers increased risk of cardiovascular disease and obese patients often have numerous other comorbidities that can affect surgical outcome. Accordingly, surgical complications and outcomes in obese patients may be deleteriously affected by both direct and indirect factors.

Specific to urethroplasty, avoiding surgical infection is a primary concern as infection is a well-known cause for surgical failure (7). Further, given that a successful urethroplasty requires a well-vascularized urethra [excision and primary anastomosis (EPA)] or graft bed (buccal), the presence of cardiac or vascular disease may, in theory, deleteriously impact recurrence rates following repair (9). 
Table 1 Patient and surgical characteristics $(n=137)$

\begin{tabular}{|c|c|c|c|}
\hline Characteristics & All patients $(n=137)$ & Recurrence $(n=23)$ & No recurrence $(n=114)$ \\
\hline BMI, mean $( \pm \mathrm{SD})\left(\mathrm{kg} / \mathrm{m}^{2}\right)$ & $29.2( \pm 7.7)$ & $28.9( \pm 7.2)$ & $30.4( \pm 10.2)$ \\
\hline Follow-up, mean ( \pm SD) (months) & $91.8( \pm 30.5)$ & $91.4( \pm 31.8)$ & $94.2( \pm 22.1)$ \\
\hline Stricture length, mean $( \pm \mathrm{SD})(\mathrm{cm})$ & $2.9( \pm 2.8)$ & $2.9( \pm 2.8)$ & $2.6( \pm 2.7)$ \\
\hline Anterior & $106[77]$ & 15 [65] & $91[80]$ \\
\hline Posterior & 18 [13] & $4[17]$ & 14 [12] \\
\hline Combined & $13[9]$ & $4[17]$ & $9[8]$ \\
\hline \multicolumn{4}{|l|}{ Etiology, n [\%] } \\
\hline Trauma & $28[20]$ & 3 [13] & 25 [22] \\
\hline Dermatologic/infectious & $14[10]$ & $4[17]$ & $10[9]$ \\
\hline Hypospadias & $8[6]$ & $3[13]$ & $5[4]$ \\
\hline \multicolumn{4}{|l|}{ Repair type, n [\%] } \\
\hline EPA & $62[45]$ & $10[43]$ & $52[46]$ \\
\hline Buccal & $45[33]$ & 9 [39] & 36 [32] \\
\hline FC & $27[20]$ & $4[17]$ & $23[20]$ \\
\hline Combined & 3 [2] & $0[0]$ & 3 [3] \\
\hline
\end{tabular}

$\mathrm{P}=\mathrm{NS}$, all calculations. EPA, excision and primary anastomosis; FC, fasciocutaneous.

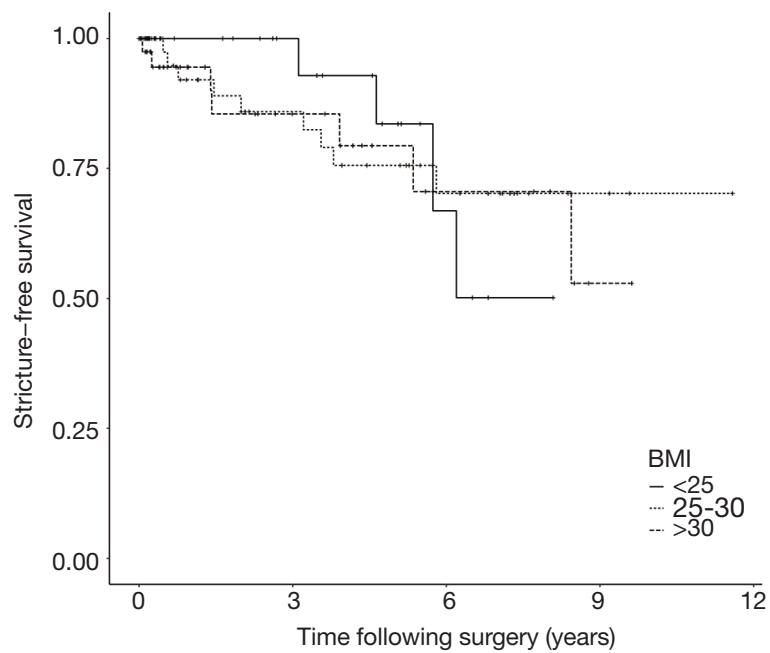

Figure 1 Kaplan-Meier plot (stricture-free survival). BMI, body mass index.
Given the previously described association of BMI with both infection and vascular disease, BMI itself is a potential risk factor of surgical failure following urethroplasty. Accordingly, research evaluating this possible risk is important to help understand outcomes and guide surgical planning.

The present investigation showed no statistically significant difference in BMI in comparison of patients experiencing recurrence versus recurrence-free status. Further, both univariate and multivariate analysis failed to demonstrate BMI as a predictive variable for stricture recurrence. On multivariate analysis, FC repair type demonstrated a protective effect from stricture recurrence. In all other analyses, additional variables were predictive of stricture recurrence.

Our data differ somewhat from those presented previously. Privratsky et al. demonstrated increased recurrence rates following buccal or lingual urethroplasty in comparison of patients with $\mathrm{BMI}>35 \mathrm{~kg} / \mathrm{m}^{2}(10)$. 
Table 2 Potential predictors for stricture recurrence, univariate analysis

\begin{tabular}{lcc}
\hline Predictors & OR $(95 \% \mathrm{Cl})$ & P value \\
\hline Age & $1.02(0.99-1.05)$ & 0.20 \\
BMI & $1.03(0.98-1.10)$ & 0.20 \\
Stricture length & $0.97(0.78-1.15)$ & 0.78 \\
Stricture location* & & \\
Posterior & $2.70(0.45-5.63)$ & 0.38 \\
Combined & $1.73(0.66-9.49)$ & 0.13 \\
Etiology & & \\
Idiopathic & $0.90(0.12-18.30)$ & 0.93 \\
latrogenic & $1.08(0.13-23.20)$ & 0.95 \\
Trauma & $0.60(0.06-13.50)$ & 0.68 \\
Hypospadias & $3.00(0.27-73.10)$ & 0.40 \\
Repair type & & \\
EPA & $0.86(0.32-2.34)$ & 0.77 \\
FC & $0.32(0.05-1.37)$ & 0.17 \\
\hline$*$
\end{tabular}

*, anterior location modeled as control; ${ }^{* *}, \mathrm{BXO}$ etiology modeled as control; ${ }^{* * *}$, buccal repair type modeled as control. $\mathrm{BMI}$, body mass index; EPA, excision and primary anastomosis; $\mathrm{FC}$, fasciocutaneous.

Ekerhult and colleagues evaluated risks for failure of penile urethroplasty and demonstrated that BMI $>30 \mathrm{~kg} / \mathrm{m}^{2}$ was a predictor for failure of one-stage urethroplasty (11). However, BMI $>30 \mathrm{~kg} / \mathrm{m}^{2}$ was not a predictor for failure of two-stage urethroplasty on multivariate analysis.

Similarly, Breyer et al. demonstrated that overweight (BMI: $25-30 \mathrm{~kg} / \mathrm{m}^{2}$ ) and obese (BMI: $30-35 \mathrm{~kg} / \mathrm{m}^{2}$ ) cohorts had increased risk of urethroplasty failure (12). Interestingly, patients with severe (BMI: $35-40 \mathrm{~kg} / \mathrm{m}^{2}$ ) or morbid $\left(\mathrm{BMI}>40 \mathrm{~kg} / \mathrm{m}^{2}\right)$ obesity did not have increased risk of urethroplasty failure. The authors hypothesize that this non-linear relationship between BMI may relate to the more sedentary status of the morbidly obese patient and that this protects against activities that may promote urethroplasty failure. This finding is interesting given other investigation identifying an "obesity paradox" where moderate obesity confers a protective influence on adverse events (13).

Combined, these data demonstrate the need to further clarify the effect of obesity on urethroplasty outcomes. In addition to furthering the surgical community's understanding of urethroplasty outcomes, these data are of
Table 3 Potential predictors for stricture recurrence, multivariate analysis

\begin{tabular}{lcc}
\hline Predictors & OR $(95 \% \mathrm{Cl})$ & P value \\
\hline Age & $1.02(0.99-1.07)$ & 0.22 \\
BMI & $1.00(0.92-1.09)$ & 0.93 \\
Stricture length & $0.75(0.55-0.98)$ & 0.06 \\
Stricture location & & \\
Posterior & $2.77(0.35-24.10)$ & 0.33 \\
Combined & $2.49(0.22-24.20)$ & 0.44 \\
Etiology & & \\
Idiopathic & $0.31(0.02-8.61)$ & 0.49 \\
latrogenic & $0.12(0.02-10.32)$ & 0.41 \\
Trauma & $0.13(0.004-4.97)$ & 0.23 \\
Hypospadias & $3.50(0.14-142.30)$ & 0.46 \\
Repair type & & \\
EPA & $0.59(0.13-2.64)$ & 0.49 \\
FC & $0.07(0.002-0.62)$ & 0.047 \\
\hline
\end{tabular}

$\mathrm{BMI}$, body mass index; EPA, excision and primary anastomosis; FC, fasciocutaneous.

significant practical importance as well. Indeed, until more robust data is available, it is possible that obese patients may be unnecessarily counseled towards repeat dilation or incision given surgeon concerns regarding outcome. Given the documented underutilization of urethroplasty and lack of access to urethroplasty surgeons, it is important that the surgical community continue efforts to limit barriers to urethroplasty (14). This is particularly true given analysis demonstrating that early urethroplasty is more cost-effective and efficacious when compared to repeated internal urethrotomy (15).

Study limitations include population sample and followup duration. It is possible that increased study duration may capture additional recurrences that would improve study power. However, prior investigation suggests that most recurrences are seen within the follow-up period of our study. Accordingly, Privratsky and colleagues reported that all recurrences were diagnosed within 1 year of urethroplasty (10). Similarly, Breyer et al. found that the majority of urethroplasty failures were identified within 2 years of surgery (12). While stricture recurrence is also reported in a delayed fashion, these data suggest that our follow-up period is adequate (16). 
In addition, the diversity of our study population may affect our results. Our cohort included patients undergoing a variety of surgical repair types in varying urethral locations. Other authors have presented data assessing the effect of BMI on urethroplasty outcome in specific cohorts, including focus on grafted urethroplasty (buccal/ lingual) and isolated penile strictures $(10,11)$. While focused analysis in specific cohorts can be helpful, these studies also often have more limited patient numbers as a result and power deficiencies that may affect study conclusions. The study population size is strength of the present study and represents a larger experience reported to date with focus on BMI. Indeed, there is a paucity of literature focused on BMI as it relates to urethroplasty complications and outcomes. Further, our investigation is an important addition to existing literature as they suggest that BMI may not be a significant predictor for urethroplasty failure.

\section{Conclusions}

In our study, BMI did not independently predict for stricture recurrence following urethroplasty. Further research is needed to evaluate the possible influence of BMI on complications and outcomes following urethroplasty.

\section{Acknowledgements}

None.

\section{Footnote}

Conflicts of Interest: The authors have no conflicts of interest to declare.

Ethical Statement: University of Virginia Institutional Review Board (IRB) approval was obtained for study protocol (IRB\#17303).

\section{References}

1. The NHS Information Centre. Statistics on Obesity, Physical Activity and Diet: Heal. San Fr. 2014. Available online: https://digital.nhs.uk/data-and-information/ publications/statistical/statistics-on-obesity-physicalactivity-and-diet/statistics-on-obesity-physical-activityand-diet-england-2014

2. Centers for Disease Control and Prevention. Adult Obesity Facts. Data \& Statistics. 2015. Available online: http://www.cdc.gov/obesity/data/

3. Joshi GP, Ahmad S, Riad W, et al. Selection of obese patients undergoing ambulatory surgery: a systematic review of the literature. Anesth Analg 2013;117:1082-91.

4. Pasulka PS, Bistrian BR, Benotti PN, et al. The risks of surgery in obese patients. Ann Intern Med 1986;104:540-6.

5. Visscher TL, Seidell JC. The public health impact of obesity. Annu Rev Public Health 2001;22:355-75.

6. Mundy AR, Andrich DE. Urethral strictures. BJU Int 2011;107:6-26.

7. Hampson LA, McAninch JW, Breyer BN. Male urethral strictures and their management. Nat Rev Urol 2014;11:43-50.

8. Dobner J, Kaser S. Body mass index and the risk of infection - from underweight to obesity. Clin Microbiol Infect 2018;24:24-8.

9. Levy M, Gor RA, Vanni AJ, et al. The Impact of Age on Urethroplasty Success. Urology 2017;107:232-8.

10. Privratsky JR, Almassi N, Guralnick ML, et al. Outcomes of grafted bulbar urethroplasty in men with class II or III obesity. Urology 2011;78:1420-3.

11. Ekerhult TO, Lindqvist K, Peeker R, et al. Limited experience, high body mass index and previous urethral surgery are risk factors for failure in open urethroplasty due to penile strictures. Scand J Urol 2015;49:415-8.

12. Breyer BN, McAninch JW, Whitson JM, et al. Effect of obesity on urethroplasty outcome. Urology 2009;73:1352-5.

13. Nepogodiev D, Chapman SJ, Glasbey J, et al. Determining Surgical Complications in the Overweight (DISCOVER): a multicentre observational cohort study to evaluate the role of obesity as a risk factor for postoperative complications in general surgery. BMJ Open 2015;5:e008811.

14. Consolo MJ, Syed KK, Robison C, et al. Barriers to accessing urethroplasty. Rev Urol 2016;18:188-93 .

15. Greenwell TJ, Castle C, Andrich DE, et al. Repeat urethrotomy and dilation for the treatment of urethral stricture are neither clinically effective nor cost-effective. J Urol 2004;172:275-7.

16. Wood DN, Andrich DE, Greenwell TJ, et al. Standing the test of time: the long-term results of urethroplasty. World J Urol 2006;24:250-4.

Cite this article as: Rapp DE, Mills JT, Smith-Harrison LI, Smith RP, Costabile RA. Effect of body mass index on recurrence following urethroplasty. Transl Androl Urol 2018;7(4):673-677. doi: 10.21037/tau.2018.06.07 